\title{
Interleukin-1 and Nitric Oxide Protect Against Tumor Necrosis Factor $\alpha$-Induced Liver Injury Through Distinct Pathways
}

\author{
Ines Bohlinger, Marcel Leist, Johannes Barsig, Stefan Uhlig, Gisa Tiegs, and Albrecht Wendel
}

\begin{abstract}
Mice sensitized with D-galactosamine (GalN) and challenged with recombinant murine tumor necrosis factor $\alpha($ TNF $\alpha)$ developed severe apoptotic and secondary necrotic liver injury as assessed by histology, measurement of cytosolic DNA fragments, and determination of liver specific enzymes in plasma. Pretreatment with recombinant human interleukin-1 $\beta$ (IL-1) rendered mice insensitive to this TNF $\alpha$ toxicity. Coadministration of the liver-specific transcriptional inhibitor GalN with $\mathbf{L}$ 1 prevented the development of tolerance, implicating de novo synthesis of liver specific proteins in the induction of tolerance. Pretreatment of mice with IL-1 resulted in elevated levels of nitrite/nitrate in serum and in enhanced nitric oxide synthase (NOS) activity in liver cells isolated from these animals. In addition, pharmacological doses of the nitric oxide (NO) donor sodium nitroprusside conferred complete protection against TNF $\alpha$ induced liver injury in galactosamine-sensitized mice, suggesting a possible link between $\mathrm{IL}-1$ - and NO-induced protection. However, prevention of NO-synthesis by $N^{G}$-monomethyl-L-arginine (NMMA) did not abolish IL-1-induced tolerance to TNF $\alpha$ in vivo. Cytotoxicity of TNF $\alpha$ to isolated hepatocytes sensitized with actinomycin $D$ (ActD) was not significantly altered by inhibition of endogenous nitrite release. Also, enhanced NO production elicited in vitro by glycerol trinitrate or ex vivo by pretreatment with $\mathrm{IL}-1$ had no significant effect in this system. We conclude that $1 \mathrm{~L}-1-$ and NO-induced protection of mice against TNF $\alpha$-mediated liver damage follow distinct pathways.
\end{abstract}

Abbreviations: LPS, lipopolysaccharides; TNF $\alpha$, tumor necrosis factor $\alpha$; GalN, D-galactosamine; ActD, actinomycin D; IL-1, interleukin- $1 \beta ; \mathrm{NO}$, nitric oxide; NOS, NO synthase; SNP, sodium nitroprusside; ELISA, enzyme-linked immunosorbent assay; LDH, lactic dehydrogenase; MTT, 3-[4,5-dimethylthiazol-2-yl]-2,5-diphenyltetrazolium bromide; NMMA, $N^{G}$ monomethyl-L-arginine.

From the Faculty of Biology, University of Konstanz, D-78434 Konstanz, Germany.

Received December 13, 1994; accepted August 8, 1995.

Supported by the Deutsche Forschungsgemeinschaft, Bonn, Germany, Sonderforschungsbereich 156 (Mechanisms of cellular communication), grant no. We 686/15-1.

Address reprint requests to: Albrecht Wendel, $\mathrm{PhD}$, Biochemical Pharmacology, Faculty of Biology, University of Konstanz, POB 5560-M668, D-78434 Konstanz, Germany.
Bacterial endotoxins (lipopolysaccharides [LPS]), as well as constituents from gram-positive bacteria, fungi, protozoa, or viruses, exert their proinflammatory effects by inducing the production of a variety of endogenous mediators in the host. Tumor necrosis factor $\alpha$ (TNF $\alpha$ ) has been recognized as one of the key inflammatory mediators in various experimental settings and has been shown to mediate lethal shock and multiorgan failure (for review see reference 1).

Various animal models have been developed to study organ injury induced by TNF $\alpha$. We and others have used mice sensitized to LPS or TNF $\alpha$ by transcriptional inhibitors such as D-galactosamine (GalN) ${ }^{2,3}$ or actinomycin D (ActD). ${ }^{4}$ In analogy to data from experiments carried out in vivo, ActD has been shown to sensitize cell lines up to 10,000-fold towards TNF $\alpha$. An essential feature of the in vivo models is that during transcriptional inhibition otherwise subtoxic doses of TNF $\alpha$ result in a relatively selective liver damage which allows quantitative assessment of TNF $\alpha$-toxicity by measurement of plasma enzymes. ${ }^{3}$ In the GalN model, animals can be completely desensitized to an otherwise lethal challenge of either LPS or TNF $\alpha$ by pretreatment with LPS, TNF $\alpha$, or interleukin $1 \beta$ (IL-1). ${ }^{5}$ Of these agents, IL-1 was shown to be the most potent tolerance-inducing agent to TNF $\alpha$ challenge in GalN-sensitized animals. ${ }^{5}$

Although the mediators and mechanisms of tolerance may have important clinical implications, the phenomenon is not well understood. Tolerance is best characterized at the level of macrophages, which release a reduced spectrum of mediators upon LPS stimulation after desensitization with LPS. ${ }^{6}$ However, this mechanism alone is unlikely to account for tolerance to direct administration of TNF $\alpha$ in vivo. ${ }^{5}$

Circumstantial evidence suggests the involvement of nitric oxide (NO) (for review see reference 7), a pleiotropic endogenous mediator, in the development of tolerance to LPS- or cytokine-induced toxicity. Stimulation with cytokines was shown to induce NO production by endothelial cells, ${ }^{8}$ macrophages, ${ }^{9}$ hepatocytes, ${ }^{10-12}$ and Ito cells. ${ }^{13}$ Moreover, it was shown that endogenously produced NO reduced organ injury or mortality in various models of septic organ failure and shock, such as endotoxin-induced liver damage, glomerular thrombosis, or endotoxin shock. ${ }^{14-17}$ 
Because IL-1 is both a strong inducer of NO synthases (NOS) ${ }^{18,19}$ and a potent agent for induction of tolerance, ${ }^{5,20,21}$ in this study we investigated whether there is a causal relation between IL-1-mediated tolerance to $\mathrm{TNF} \alpha$-induced liver damage and NO formation. The first aim of this study was to check whether tolerance induction results in an increase in NOS-activity. Secondly, we examined whether or not NOS induction was responsible for IL-1-mediated tolerance to $\mathrm{TNF} \alpha$ in GalN-sensitized mice, i.e., in a model in which toxicity is unlikely to be primarily initiated by LPS-induced endogenous cytokine production.

\section{MATERIALS AND METHODS}

Animal Experiments. Male Bagg Albino/c mice were supplied by the animal house of the University of Konstanz, Germany. Animals were kept at $22^{\circ} \mathrm{C}$ and $55 \%$ relative humidity in a 12-hour day-night rhythm with free access to food (Altromin 1313; Altromin Co., Lage, Germany) and water. 16 hours before in vivo experiments food was withdrawn. For hepatocyte isolation, fed Bagg Albino/c mice were used. All animals received humane care in compliance with the guidelines of the local authorities.

Treatment Schedules. All substances were administered in pyrogen-free saline. LPS (Roth, Karlsruhe, Germany), sodium nitroprusside (SNP) (Fluka, Buchs, Switzerland), and GalN (Roth) were injected intraperitoneally in a volume of $200 \mu \mathrm{L}$, recombinant human IL-1 $\beta$ (a gift from Dr K. Vosbeck, Ciba-Geigy, Basel, Switzerland), recombinant murine TNF $\alpha$ (a gift from Dr Adolf, Bender \& Co., Vienna, Austria) and NMMA (Sigma Chemical Co., St. Louis, MO) were injected intravenously in a volume of $300 \mu \mathrm{L}$. Animals were killed by cervical dislocation 8 hours after challenge, and blood was withdrawn by cardiac puncture into heparinized syringes.

DNA-Fragmentation. Livers were perfused for 10 seconds with cold perfusion buffer $(50 \mathrm{mmol} / \mathrm{L}$ phosphate, $120 \mathrm{mmol} /$ $\mathrm{L} \mathrm{NaCl}, 10 \mathrm{mmol} / \mathrm{L}$ ethylenediaminetetraacetic acid, $\mathrm{pH} 7.4$ ), before they were excised. One slice of the large anterior lobe was immediately fixed in $4 \%$ formalin for histological studies. The remaining parts of the liver were disintegrated with three strokes of an Elvehjem type homogenizer. The $20 \%$ homogenate (in perfusion buffer) was centrifuged at $13,000 \mathrm{~g}$ for 20 minutes. The supernatant was further diluted 250 -fold. DNA fragmentation was quantified by measuring cytosolic oligonucleosome-bound DNA using an enzyme-linked immunosorbent assay (ELISA) kit (Boehringer, Mannheim, Germany). ${ }^{22}$ Briefly, the cytosolic fraction $(13,000 \mathrm{~g}$ supernatant) from about $75 \mu \mathrm{g}$ of liver was used as antigen source in a sandwich ELISA with a primary antihistone antibody coated to the microtiter plate and a secondary anti-DNA antibody coupled to peroxidase.

Histology. Formalin-fixed liver slices were imbedded in paraplast. 2 - to $3-\mu \mathrm{m}$ sections were stained with hematoxylin/ eosin.

Cell Culture and Incubation Conditions. Hepatocytes were isolated from 12-week-old male Bagg Albino/c mice by the two-step collagenase perfusion method according to Seglen, ${ }^{23}$ modified by Klaunig et al. ${ }^{24}$ Nonparenchymal liver cells, containing about 50\% macrophages, were prepared by differential centrifugation according to Doolittle and Richter. ${ }^{25}$ Viability of cells exceeded $80 \%$ as determined by Trypan blue exclusion. Hepatocytes were plated in $200 \mu \mathrm{L}$ of RPMI 1640 medium supplemented with $10 \%$ newborn calf serum (Bio- chrom, Berlin, Germany) in 24-well plates at a density of 8 $\times 10^{4}$ hepatocytes per well. Nonparenchymal cells were plated in the same medium as hepatocytes at a density of 2 $\times 10^{5}$ cells per well in 24 -well plates. Cells were allowed to adhere to culture plates for 5 hours before the medium was exchanged for RPMI 1640 medium without serum. Substances were added as stock solutions in a volume of $50 \mu \mathrm{L}$ of RPMI 1640 per well. Incubations were performed for the periods indicated at $37^{\circ} \mathrm{C}$ in an atmosphere consisting of $5 \%$ $\mathrm{CO}_{2}, 40 \% \mathrm{O}_{2}$, and $55 \% \mathrm{~N}_{2}$

Enzyme Assays. Activities of alanine aminotransferase, aspartate aminotransferase, and sorbitol dehydrogenase in plasma and lactate dehydrogenase (LDH) in cell supernatants and lysates were determined according to Bergmeyer, ${ }^{26}$ using an Eppendorf (Hamburg, Germany) ACP 5040 enzyme analyzer.

Cell Viability Assays. Cytotoxicity was expressed as the proportion of $\mathrm{LDH}$ released into medium compared with the total amount of LDH present in the cells as determined by lysis of cells with $0.1 \%$ Triton X-100. ${ }^{27}$

The 3-[4,5-dimethylthiazol-2-yl]-2,5-diphenyltetrazolium bromide (MTT) assay was performed essentially according to Mosmann. ${ }^{28}$ Briefly, hepatocytes cultured in 24-well plates were incubated for 30 minutes with MTT $(0.4 \mathrm{mg} / \mathrm{mL}$ final concentration, Sigma Chemical Co), medium was discarded and the cells were lysed in $200 \mu \mathrm{L}$ 95/5: i-propanol/formic acid. An aliquot of $100 \mu \mathrm{L}$ was transferred to 96-well microtiter plates and measured at 560/690 $\mathrm{nm}$ on an ELISA-reader. MTT-toxicity was defined as:

$$
\text { toxicity }[\%]=(100 \%)-(100 \%) \times \frac{\text { Absorbance }_{\text {tox }}}{\text { Absorbance }_{\text {control }}} \text {. }
$$

TNF $\alpha$ Assay. TNF $\alpha$ in liver cell supernatants was determined essentially as described in Espevik and NissenMeyer, ${ }^{29}$ using recombinant murine TNF $\alpha$ as a standard.

Nitrite Determination in Cell Culture Supernatants. For determination of nitrite release cells were incubated for 20 hours in RPMI 1640 medium without phenol red. Culture supernatants were assayed for nitrite by the Griess reaction: briefly, $200 \mu \mathrm{L}$ culture supernatant were transferred to $96-$ well microtiter plates, $20 \mu \mathrm{L}$ sulfanilamide $(1 \%$ in $1.2 \mathrm{~mol} / \mathrm{L}$ $\mathrm{HCl}$, Sigma Chemical Co.), and $20 \mu \mathrm{L} N$-(1-naphthyl) ethylendiamine $\left(0.1 \%\right.$ in $\mathrm{H}_{2} \mathrm{O}$, Sigma Chemical $\mathrm{Co}$.) were added and absorbance was read after 3 minutes' incubation time at 560/ $690 \mathrm{~nm}$ on an ELISA-reader. The nitrite content in the culture supernatant increased linearly within the time span of 20 hours investigated.

Nitrite Determination in Serum. Nitrite in serum was measured essentially according to the method of Misko et al, ${ }^{30}$ using the Griess assay instead of the fluorimetric assay described. Briefly, plasma obtained by cardiac puncture into heparinized syringes was filtered through an Ultrafree-MC microcentrifuge filter unit (Millipore, Bedford, MA) for 1 hour at $14,000 \mathrm{rpm}$ to remove hemoglobin released by cell lysis, which might interfere with the colorimetric assay. Because nitrite in serum is mostly oxidized to nitrate by reaction with the iron-heme center of hemoglobin, the resulting nitrate was first reduced to nitrite by incubation with nitrate reductase from aspergillus species (Sigma Chemical Co). Fourteen million units of nitrate reductase (in $20 \mathrm{mmol} / \mathrm{L}$ Tris/ $\mathrm{HCl}, \mathrm{pH}$ 7.6) were added to $10 \mu \mathrm{L}$ of filtrate, and the reaction was started by addition of nicotinamide adenine dinucleotide phosphate in Tris/HCl-buffer to a final concentration of 40 $\mu \mathrm{mol} / \mathrm{L}$ and a final volume of $50 \mu \mathrm{L}$. After 5 minutes incuba- 


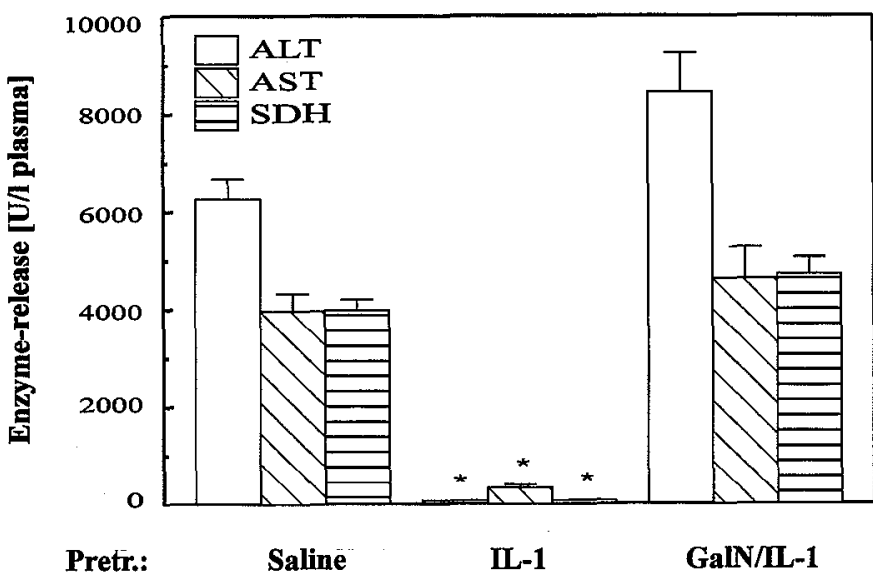

FIG. 1. IL-1-induced tolerance against TNF $\alpha$-mediated liver injury in galactosamine-sensitized mice. Animals were challenged with rmuTNF $\alpha(10 \mu \mathrm{g} / \mathrm{kg}$, intravenous) and GalN (700 mg/kg, intraperitoneal) $4 \mathrm{~h}$ after pretreatment (Pretr.). IL-1 was administered intravenously in a dose of $10 \mu \mathrm{g} / \mathrm{kg}$ either alone or together with GalN (700 $\mathrm{mg} / \mathrm{kg}$, intraperitoneal). ALT, aspartate-aminotransferase (AST) and sorbitol dehydrogenase (SDH) were measured 8 hours after GalN/ $\mathrm{TNF} \alpha$ challenge. In control experiments, in which mice were treated with GalN/LL-1 and a second dose of GalN without TNF $\alpha$, no liver damage was observed. Data are expressed as mean values \pm SEM $\mathrm{n}=6 . * P<.05$ vs. pretreatment with saline.

tion at room temperature, the reaction was terminated by dilution with $50 \mu \mathrm{L}$ of distilled water. The whole reaction volume was transferred to 96 -well microtiter plates, $10 \mu \mathrm{L}$ sulfanilamide ( $1 \%$ in $1.2 \mathrm{~mol} / \mathrm{L} \mathrm{HCl})$, and $10 \mu \mathrm{L} N$-(1-naphthyl) ethylenediamine $\left(0.1 \%\right.$ in $\left.\mathrm{H}_{2} \mathrm{O}\right)$ were added and absorbance was read after 3 minutes ${ }^{3}$ incubation time at 560/ $690 \mathrm{~nm}$ on an ELISA reader.

Statistics. Data from in vivo experiments are given as mean \pm SEM, all other data as mean \pm SD. Data for transaminases and DNA-fragmentation were analyzed by nonparametric analysis of variance (Kruskal-Wallis). Where there were differences among the groups $(P<.05)$, these were subjected to one-sided nonparametric multiple comparisons of the control against all other groups. ${ }^{31}$ Statistical analysis of nitrite/nitrate concentrations (Tables 2 and 3) was done using the parametric Waller-Duncan test. $P<.05$ was considered to be significant.

\section{RESULTS}

IL-1-Induced Tolerance to GalN/TNF-Mediated Liver Damage. Intravenous administration of recombinant murine TNF $\alpha(10 \mu \mathrm{g} / \mathrm{kg})$ to GalN-sensitized male $\mathrm{BALB} / \mathrm{c}$ mice induced severe necrotic liver damage as determined by elevated plasma levels of liver enzymes 8 hours after challenge (Fig. 1). Apoptotic changes preceded liver necrosis by several hours. After 5 hours, oligonucleosomal cytosolic DNA-fragments in livers of GalN/TNF challenged mice were increased $2.9 \pm 0.7-$ fold compared with livers treated with GalN only. Eight hours after challenge, i.e., at the time when blood was withdrawn for assessment of liver injury by clinical chemistry, DNA-fragmentation was increased 3.6 \pm 0.4-fold§ compared with controls (data \pm SEM, $n$
$=3, \S P<.05$ vs. GalN-treated control). Histological examination confirmed these findings and their interpretation; 3.5 hours after injection of TNF $\alpha$ to GalNsensitized mice, hyperchromatic nuclear membranes and formation of apoptotic bodies were observed. Eight hours after TNF, numerous apoptotic bodies were identified between necrotic hepatocytes (Fig. 2). In contrast, pretreatment of the animals with $10 \mu \mathrm{g} / \mathrm{kg}$ recombinant human IL- $1 \beta$ intravenously 4 hours before challenge led to a completely refractory state with respect to TNF $\alpha$-induced cytotoxicity in GalN-sensitized mice; i.e., no significant transaminase release into plasma occurred at 5 hours or at 8 hours after TNF $\alpha$ administration (Fig. 1) and DNA-fragmentation was not significantly increased at 5 hours ( $130 \pm 10 \%$ of GalN control) and 8 hours $(110 \pm 10 \%)$. Nevertheless, numerous infiltrating neutrophils were present in the liver of IL-1pretreated mice 8 hours after challenge with GalN and TNF (Fig. 2). IL-1-pretreated mice went through a period of illness characterized by reduced motility and piloerection. However, the animals recovered from these symptoms within a few hours. When we varied the interval between IL-1 pretreatment and challenge, we found that tolerance started as early as 1 hour after IL-1 pretreatment and lasted for at least 48 hours (data not shown).

Prevention of IL-1 Induced Tolerance by Inhibition of Hepatic Transcription. Cytokine producing macrophages were not rendered refractory by IL-1 pretreatment. In fact, spontaneous $\mathrm{TNF} \alpha$ release from liver macrophages prepared from tolerant mice was significantly enhanced $\left(1.2 \pm 0.8 \mathrm{ng} / 10^{6}\right.$ cells $)$ compared with cells from untreated controls $\left(0.7 \pm 0.2 \mathrm{ng} / 10^{6}\right.$ cells $)$. LPS-induced TNF $\alpha$-release from IL-1-pretreated mice was not significantly different from that released from Kupffer cells of control mice $(9.0 \pm 1.8$ vs. $9.9 \pm 2.8 \mathrm{ng} /$ $10^{6}$ cells). These data suggest that tolerance induced by IL-1 may be confined to the target of $\mathrm{TNF} \alpha$-mediated cytotoxicity, i.e., liver parenchymal cells. To study the role of hepatic transcription in the development of tolerance, the liver-specific transcriptional inhibitor GalN was applied together with IL-1. This treatment protocol prevented IL-1-induced tolerance to a subsequent challenge with GalN and $\mathrm{TNF}_{\alpha}$ (Fig. 1), i.e., we observed fulminant hepatic failure caused by GalN/TNF $\alpha$ in spite of a preceding treatment with a dose of IL-1 that otherwise would have provided complete protection against $\mathrm{TNF} \alpha$ challenge.

Protection Against GalN/TNFa-Induced Liver Damage by Administration of SNP. Liver NOS is one of the putatively protective proteins ${ }^{14-17}$ known to be induced by IL-1. ${ }^{10,12,19}$ To study possible participation of NO in the development of tolerance, we first tested the efficacy of the pharmacological NO donor SNP against liver damage induced by $\mathrm{TNF} \alpha$ in GalN-sensitized mice. GalN-sensitized mice treated with SNP (1.7 mg/ $\mathrm{kg}, 15$ minutes before challenge) were protected against liver damage induced by recombinant murine TNF $\alpha(10 \mu \mathrm{g} / \mathrm{kg})$ (Table 1). Thus, endogenous NO pro- 

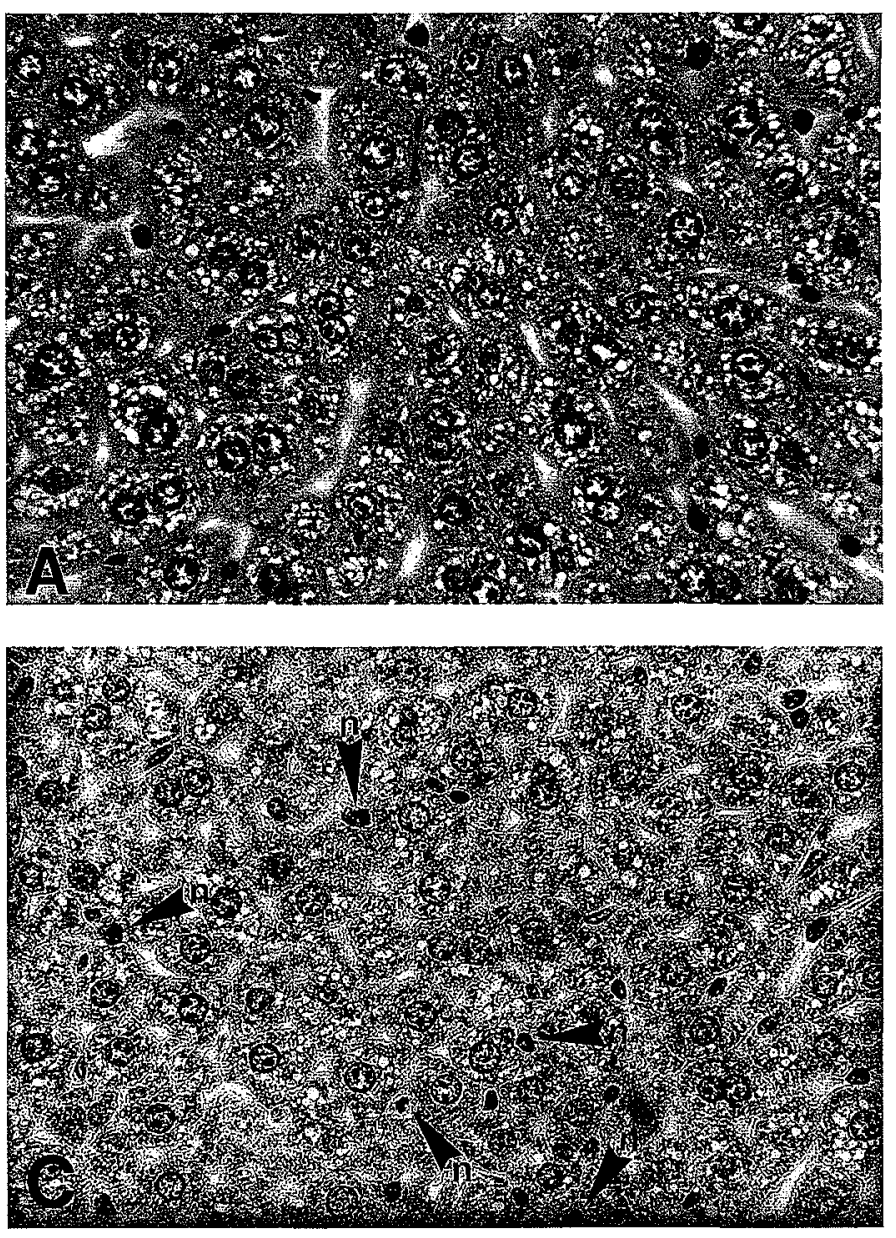

duction from exogenous precursors has the potential to protect against TNF $\alpha$-mediated toxicity. Although the animals showed very pronounced hypotension and vasodilatation over a period of 20 minutes after SNP administration, no elevated nitrate/nitrite levels were detectable in plasma 15 minutes or 2 hours after injection of SNP. This is explained by the fact that the maximal attainable NO concentration $(9 \mu \mathrm{mol} / \mathrm{L})$ after this dose of SNP (170 nmol/mouse) is below the detection limit of the Griess assay.

Table 1. Protection by SNP.Pretreatment Against TNFInduced Liver Failure in Galactosamine-Sensitized Mice

\begin{tabular}{lcccc}
\hline Pretreatment $^{*}$ & ALT $_{\dagger}$ (U/L) & AST (U/L) & SDH (U/L) & n $\ddagger$ \\
\hline Saline & $8470 \pm 4120$ & $2920 \pm 1100$ & $3650 \pm 1580$ & 4 \\
SNP & $111 \pm 25 \S$ & $446 \pm 423 \S$ & $123 \pm 28 \S$ & 5 \\
\hline
\end{tabular}

* SNP was given intraperitoneally in a dose of $1.7 \mathrm{mg} / \mathrm{kg} 15 \mathrm{~min}-$ nutes before challenge ( $700 \mathrm{mg} / \mathrm{kg}$ GalN, intraperitoneal, plus $10 \mu \mathrm{g} /$ $\mathrm{kg}$ TNF $\alpha$, intravenous).

$\dagger$ ALT, aspartate aminotransferase (AST), and sorbitol dehydrogenase (SDH) were measured 8 hours after challenge, data are expressed as means \pm SEM

$\ddagger \mathrm{n}=$ number of animals per group.

$\S P<.05$.

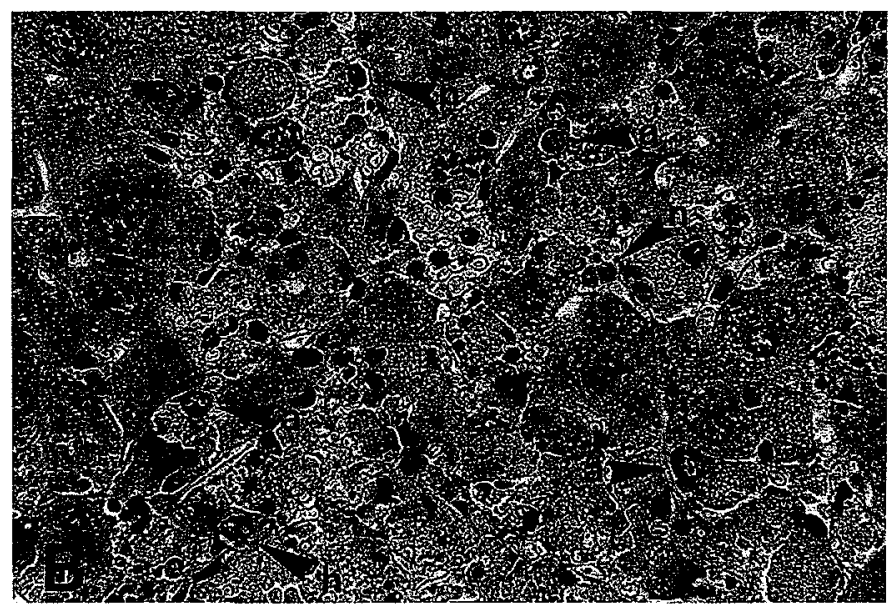

FrG. 2. Histopathology of TNF $\alpha$-induced liver damage in D-galactosamine-sensitized mice. Influence of IL-1 pretreatment. Liver sections were prepared after treatment of mice for (A) 8 hours with GalN or (B) 8 hours with GalN/TNF $\alpha$ (hyperchromatic nuclear membranes $[\mathrm{h}]$ and numerous apoptotic bodies [a] as signs of hepatocellular apoptosis are shown between necrotic hepatocytes) or (C) for 8 hours with GalN/TNF $\alpha$ after IL-1 pretreatment. Numerous infiltrating neutrophils (n) but neither apoptotic nor necrotic liver damage are visible.

IL-1-Induced Endogenous NO Production. Because pharmacologically delivered NO provided protection against TNF $\alpha$ toxicity in vivo, we checked whether NO was produced endogenously upon treatment of mice with IL-1. Male BALB/c mice were injected with either saline or IL-1 $(10 \mu \mathrm{g} / \mathrm{kg})$. Serum nitrite/nitrate levels were elevated 6 hours after administration of IL- 1 as compared with saline-treated animals (Table 2). To identify the source of IL-1-induced endogenous NO production, hepatocyte and nonparenchymal liver cell cultures from IL-1- or saline-treated animals were prepared 4 hours after pretreatment. Endogenous NO production was determined by measuring the amount of nitrite released into the culture supernatant. Hepatocytes were left untreated or were further stimulated by incubation with LPS $(10 \mu \mathrm{g} / \mathrm{mL})$ or IL-1 $(50 \mathrm{ng} / \mathrm{mL})$. Hepatocytes isolated from saline-treated animals released less than $1 \mathrm{nmol}$ nitrite $/ 10^{6}$ cells within 20 hours whereas in vivo pretreatment with IL-1 led to an increased spontaneous ex vivo nitrite production in liver cell cultures by a factor of at least five (Table 3 ). This augmented basal release was further enhanced by more than fourfold when these cells were incubated with IL-1 in vitro (Table 3). To characterize the requirements for induction of NOS activity by IL-1, animals were simul- 
TABLE 2. Effect of the NOS Inhibitor NMMA on IL-1-Induced Tolerance Against Liver Injury Caused by TNF in Galactosamine-Sensitized Mice

\begin{tabular}{|c|c|c|c|c|}
\hline Pretreatment* & Treatment $\uparrow$ & ALT (U/L) & Nitrite/nitrate $(\mu \mathrm{mol} / \mathrm{L})$ & $\mathbf{n}$ \\
\hline saline & GalN/TNF $\alpha$ & $10130 \pm 2400$ & $35 \pm 11$ & 5 \\
\hline saline & GalN & $90 \pm 9 \ddagger$ & $36 \pm 9$ & 3 \\
\hline IL-1 & GalN/TNF $\alpha$ & $22 \pm 24 \ddagger$ & $32 \pm 6$ & 5 \\
\hline IL-1 & saline & $18 \pm 15 \ddagger$ & $68 \pm 9 \S$ & 9 \\
\hline IL-1 & GalN & $29 \pm 16 \ddagger$ & $23 \pm 4$ & 5 \\
\hline IL-1 + NMMA & GalN/TNF $\alpha+$ NMMA & $35 \pm 23 \ddagger$ & $34 \pm 10$ & 5 \\
\hline IL-1 + NMMA & NMMA & $68 \pm 78 \ddagger$ & $27 \pm 12$ & 5 \\
\hline NMMA & GalN/TNF $\alpha+$ NMMA & $10380 \pm 3370$ & $27 \pm 8$ & 5 \\
\hline
\end{tabular}

NOTE. $\mathrm{n}$ = number of animals per group. ALT was measured 8 hours after challenge, levels of nitrite/nitrate in plasma were determined 6 hours after pretreatment. Nitrite levels in untreated animals were $30 \mu \mathrm{mol} / \mathrm{L}$. Data are means \pm SEM.

* Animals were pretreated 4 hours before challenge by an intravenous dose of $10 \mu \mathrm{g} / \mathrm{kg}$ IL-1 \pm NMMA (175 mg/kg) or by injection of saline.

$\dagger$ GalN (700 mg/kg) was administered intraperitoneally simultaneously with TNF $\alpha(10 \mu \mathrm{g} / \mathrm{kg}$, intravenous) and NMMA (175 mg/kg, intravenous).

$\ddagger P<.05$ vs. GalN/TNF $\alpha$ control.

$\S P<.05$ vs. all other groups.

taneously treated with the transcriptional inhibitor GalN or with the translational inhibitor cycloheximide, 4 hours before the preparation of hepatocytes. Coadministration of GalN and IL-1 did not abrogate the subsequent nitrite production from hepatocytes. Cells from these animals showed an even greater spontaneous release of NO that was further increased more than fourfold by in vitro stimulation with IL-1 (Table 3). In contrast, cells from cycloheximide/IL-1-treated animals showed no increased basal or IL-1 inducible release of nitrite compared with controls (Table 3). When cycloheximide $(50 \mu \mathrm{mol} / \mathrm{L})$ was present in vitro together with the stimulus, the further induction of NOS-activity by IL-1 was completely prevented in all experiments (data not shown). Additional experiments showed that nonparenchymal liver cell cultures prepared from the same mice by differential centrifugation and plastic adhesion produced less than 5\% per cell of the nitrite found in hepatocyte cultures, suggesting that the nitrite determined in the above experiments was predominantly derived from hepatocytes.
No Impairment of Tolerance by Inhibition of NOS In Vivo. To study the relevance of endogenously formed NO to the development of tolerance in vivo, we inhibited endogenous NO production by administration of $N^{\mathrm{G}}$ monomethyl-L-arginine (NMMA) $(2 \times 175 \mathrm{mg} / \mathrm{kg})$, a competitive inhibitor of NOS. NMMA reduced the elevated nitrate/nitrite levels caused by IL-1 pretreatment to values observed in control animals. However, administration of NMMA caused neither an altered toxicity of TNF $\alpha$ in vivo nor any modification of the IL1-induced tolerance in GalN-sensitized mice (Table 2). Interestingly, injection of GalN with or without TNF $\alpha$ 4 hours after administration of IL-1 already prevented the increase of nitrite/nitrate concentrations in serum. Because GalN is a liver specific transcriptional inhibitor, this suggests that the liver is the major source of IL-1-induced nitrite/nitrate release into plasma.

Absence of Ex Vivo Tolerance. To further explore the mechanisms of IL-1-induced target cell tolerance, we studied whether the state of tolerance induced by IL-

Table 3. Ex Vivo Nitrite Production by Hepatocytes of IL-1 Pretreated and Control Mice

\begin{tabular}{|c|c|c|c|c|}
\hline \multirow[b]{2}{*}{ Pretreatment* (in vivo) } & \multirow[b]{2}{*}{ Control } & \multicolumn{2}{|c|}{ Stimulus (in vitro) } & \multirow[b]{2}{*}{$\begin{array}{c}\text { ActD }(333 \mathbf{~ n M})+\text { TNF } \\
(100 \mathrm{ng} / \mathrm{mL}) \ddagger\end{array}$} \\
\hline & & $\begin{array}{c}\text { LPS } \\
(10 \mu \mathrm{g} / \mathrm{mL})\end{array}$ & $\begin{array}{c}\text { IL-1 } \\
(50 \mathrm{ng} / \mathrm{mL})\end{array}$ & \\
\hline Saline & $<1 \dagger$ & $1.2 \pm 0.2$ & $2.8 \pm 0.6$ & $<1$ \\
\hline IL-1 & $4.8 \pm 1.2 \S$ & $6.7 \pm 0.6 \S$ & $19.8 \pm 2.9 \S$ & $7.9 \pm 0.7 \S$ \\
\hline GalN/IL-1 & $7.5 \pm 0.9 \S \#$ & $10.7 \pm 0.5 \S \#$ & $33.7 \pm 2.1 \S \#$ & $2.3 \pm 0.3 \S \#$ \\
\hline CHX/IL-1 & $<1$ & $<1$ & $3.1 \pm 0.8$ & $<1$ \\
\hline
\end{tabular}

\footnotetext{
* Animals were pretreated 4 hours before preparation of hepatocytes. IL-1 was administered intravenously in a dose of $10 \mu \mathrm{g} / \mathrm{kg}$, GalN, and CHX were given intraperitoneally in a dose of $700 \mathrm{mg} / \mathrm{kg}$ or $40 \mathrm{mg} / \mathrm{kg}$ respectively, simultaneously with IL-1.

$\dagger$ Hepatocytes were incubated for 20 hours before the amount of nitrite was assayed in the supernatant. Data are means (nmol nitrite/ $10^{6}$ cells) $\pm \mathrm{SD}$ of triplicate incubations.

$\ddagger$ ActD was added 30 minutes before TNF $\alpha$.

$\S P<.05$ vs. saline pretreatment.

$\# P<.05$ vs. IL-1 pretreatment.
} 
1 in vivo was still present ex vivo in hepatocytes. Liver cells prepared from tolerant and nontolerant mice were compared with respect to their susceptibility to TNF $\alpha$ cytotoxicity after sensitization with the transcriptional inhibitor ActD. In this ex vivo experiment-in contrast to the protection observed that was caused by IL-1 in vivo-hepatocyte death induced by $\operatorname{ActD} / \mathrm{TNF} \alpha$ occurred to a similar extent regardless of the pretreatment (Fig. 3). Thus, the difference in spontaneous NO production between hepatocytes from IL-1-pretreated mice and cells from control animals (Table 3 ) had no significant influence on the sensitivity of liver cells to $\mathrm{TNF} \alpha$ in vitro.

Lack of Correlation Between Nitrite Release and Cytotoxicity of ActD/TNF $\alpha$ In Vitro. The finding that TNF-induced hepatocytotoxicity in ActD pretreated cells occurred independently of hepatocyte NO production was further corroborated by experiments using the NOS inhibitors NMMA or $N \omega$-nitro-L-arginine $(0.1$ $\mathrm{mmol} / \mathrm{L}$ ). In control experiments, these inhibitors were shown to completely block nitrite release from hepatocytes prepared from tolerant mice. Nevertheless, these NOS inhibitors did not significantly affect the cytotoxicity of TNF $\alpha$ in hepatocytes in the presence of ActD (Table 4). Also, the NO donor glycerol trinitrate neither protected nor sensitized hepatocytes against ActD/ $\mathrm{TNF} \alpha$-induced hepatocytotoxicity (Table 4).

\section{DISCUSSION}

A large variety of experimental models have been used to study possible mechanisms of septic shock and ensuing organ failure. LPS, as the primary initiator of

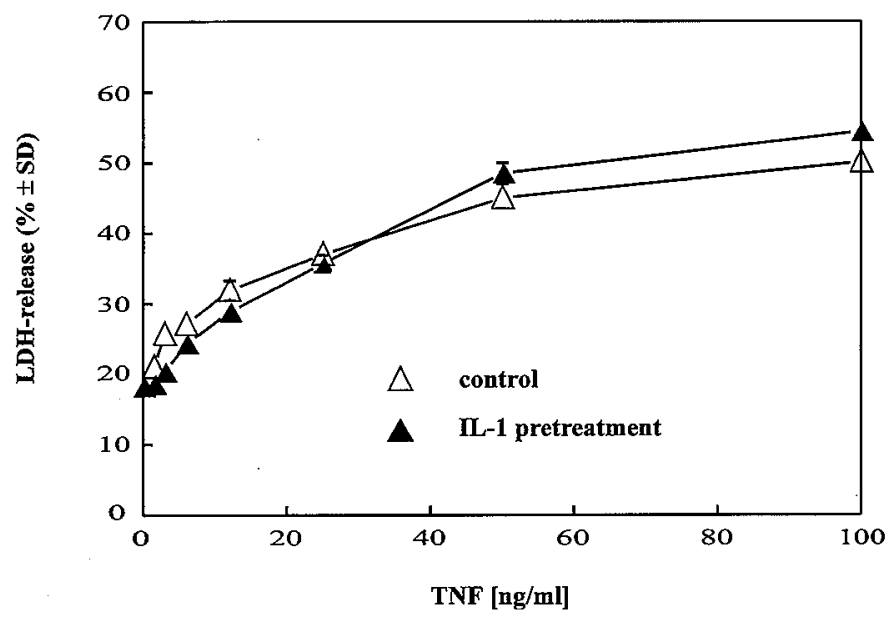

FIG. 3. TNF cytotoxicity on ActD-sensitized hepatocytes from IL1 pretreated or control mice. Hepatocytes were prepared 4 hours after pretreatment $(10 \mu \mathrm{g} / \mathrm{kg}$ IL-1, or saline). Cells were incubated with $333 \mathrm{nmol} / \mathrm{L}$ of ActD for 30 minutes before addition of TNF (1.5 to $100 \mathrm{ng} / \mathrm{mL}$ ). $\mathrm{LDH}$ release was determined after 20 hours of incubation as an indicator of cell death. Treatment with ActD alone did not induce LDH release significantly higher than that of untreated hepatocytes. Data are expressed as mean $\pm \mathrm{SD}$ of triplicate incubations.
TABLE 4. Nitrite Release and Cytotoxicity Induced by TNF in Hepatocytes Sensitized With ActD

\begin{tabular}{clcc}
\hline $\begin{array}{c}\text { In Vivo } \\
\text { Pretreatment* }\end{array}$ & In Vitro Effector $\dagger$ & $\begin{array}{c}\text { Percentage of } \\
\text { Toxicity } \$ \text { After } \\
\text { Incubation } \\
\text { With TNF/ } \\
\text { ActD }\end{array}$ & $\begin{array}{c}\text { NO }_{2} \text {-Release } \\
\text { by } \\
\text { Hepatocytes }\end{array}$ \\
\hline IL-1 & Control & $35 \pm 2$ & $4.8 \pm 1.2$ \\
IL-1 & NMMA & $36 \pm 0$ & $<\mathbf{1}$ \\
IL-1 & N $\omega$ NA & $29 \pm 3$ & $<\mathbf{1}$ \\
Saline & Solvent control & $38 \pm 2$ & $<\mathbf{1}$ \\
Saline & Glycerol trinitrate & $35 \pm 3$ & $31 \pm 4.3$ \\
\hline
\end{tabular}

NOTE. Data are means \pm SD of triplicate incubations. There is no correlation between $\mathrm{NO}_{2}$-release by hepatocytes and toxicity of TNF $\alpha$ /ActD (Pearson correlation coefficient: $0.08, P=.9$ ).

* Animals were pretreated 4 hours before preparation of hepatocytes. IL-1 was administered intravenously in a dose of $10 \mu \mathrm{g} / \mathrm{kg}$.

$\dagger$ Incubation of hepatocytes with drugs (NMMA, $0.1 \mathrm{mmol} / \mathrm{L}$; $\mathrm{N} \omega \mathrm{NA}, 0.1 \mathrm{mmol} / \mathrm{L}$; nitroglycerin $55 \mu \mathrm{mol} / \mathrm{L}$ in $0.1 \% \mathrm{EtOH})$ and stimuli was started 4 hours after hepatocyte preparation.

$\ddagger$ Determined by MTT viability assay after 20 hours' incubation. ActD $(333 \mathrm{nmol} / \mathrm{L})$ was added 30 minutes before TNF $\alpha(15 \mathrm{ng} / \mathrm{mL})$. Toxicity was compared with hepatocytes only treated with ActD.

$\$$ Amount of nitrite released into the medium in $\mathrm{nmol} / 10^{6}$ cells 20 $h$ after start of incubation.

a cytokine response, or $\mathrm{TNF} \alpha$, as a distal mediator of LPS toxicity, also in GalN-sensitized mice, ${ }^{3}$ are commonly used to elicit the systemic inflammatory response. However, pretreatment with minute amounts of either one of these agents protects mice from a second, otherwise lethal, challenge. Besides $\mathrm{TNF} \alpha$, a variety of other cytokines, such as IL-10, transforming growth factor- $\beta$, or IL-1, have been implicated in tolerance induction. ${ }^{4,5,20,32}$ In the present study, we used IL1 to induce tolerance to the TNF $\alpha$ challenge in the lowdose model of the GalN-sensitized mouse. This study design allowed us to investigate mechanisms of target cell tolerance independent of the suppression of TNF $\alpha$ release from macrophages. The dose of TNF $\alpha$ used in our experiments with GalN-sensitized mice was chosen to cause severe necrotic liver injury at about 8 hours after challenge. This protocol allows us to study acute inflammatory injury of the liver. ${ }^{33}$ In this model, we found that IL-1 caused tolerance against GalN/TNF $\alpha$ when given at any time between 1 hour and 48 hours before challenge. We chose 4 hours as the pretreatment interval to leave sufficient time between the two doses of GalN that were administered in some of the experiments (prevention of IL-1-induced tolerance by inhibition of hepatic transcription).

As with the liver failure observed in the ActD/TNF $\alpha$ model, ${ }^{22}$ a salient feature of the GalN/TNF $\alpha$ model is apoptotic and secondary necrotic liver cell death. ${ }^{34}$ Therefore, we measured both cytosolic DNA fragments and hepatocyte specific enzymes to quantitate organ injury. According to these parameters, IL-1 completely protected mice against both forms of hepatic injury induced by TNF $\alpha$. Because the development of tolerance 
could be completely abolished by coadministration of GalN, which selectively impairs the hepatic RNA synthesis $^{34}$ via trapping of uridine nucleotides and subsequent depletion of the uridine triphosphate pool, ${ }^{35}$ we conclude that IL-1-induced tolerance is an active process requiring hepatic transcription. This view is further corroborated by our finding that cytokine release of Kupffer cells prepared from IL-1-treated, tolerant animals was not impaired compared with controls. Several IL-1-inducible intrahepatic or secretory liver proteins have been described as being associated with the development of tolerance, e.g., manganese superoxide dismutase, ${ }^{36,37,38}$ or acute phase proteins like ferritin ${ }^{39}$ or $\alpha_{1}$-acid glycoprotein. ${ }^{40}$ These observations imply an active biosynthetic intrahepatic process as a cause of tolerance development.

Another putatively protective protein known to be induced by IL-1 is NOS, an enzyme producing the potent vasodilatator NO. ${ }^{14-17}$ Our finding that NOS activity is increased by incubation of murine liver cell cultures with IL-1 in vitro is in agreement with previous findings showing an induction of NOS messenger RNA in rat and human hepatocytes under similar conditions. ${ }^{12,19}$ In our experiments, enhancement of NOS activity in murine hepatocytes was suppressed by incubation with cycloheximide, suggesting induction via de novo protein synthesis. In analogy to the in vitro experiment, treatment of mice with IL-1 in vivo led to elevated levels of nitrite/nitrate in serum and to an increased NOS activity in liver cells prepared from these animals. However, the induction of NOS under the latter conditions did not render these cells tolerant to the cytotoxic action of TNF $\alpha$ in the presence of ActD. Furthermore, NOS activity ex vivo was still enhanced in cells from IL-1-treated animals in which tolerance induction was blocked by coadministration of GalN. In contrast to these ex vivo observations, in vivo the administration of GalN 4 hours after treatment of mice with IL-1 prevented the IL-1-induced increase in plasma nitrate/nitrite. Two explanations seem feasible for this obvious difference between our in vivo and ex vivo findings. In contrast to the accumulation of nitrite in vitro, nitrate and nitrite may be eliminated via urinary excretion in vivo, necessitating continous RNA and protein synthesis to maintain elevated nitrate/nitrite plasma levels. Alternatively, the nitrite release ex vivo might be explained by a rapid repletion of cellular uridine pools during the in vitro incubation, i.e., an abolition of a persistent GalN effect on transcription. In any case, our in vivo and ex vivo experiments provide additional evidence that the phenomenon of tolerance and NOS induction are separate events. Our data confirm that IL-1 induces NOS both in vivo and in vitro. However, the induction of NOS and development of tolerance seem to be simultaneous events occurring independently from each other.

The cytotoxicity of TNF $\alpha$ in hepatocyte cultures containing ActD was neither affected by inhibition of nitrite release nor by enhancement of NO-formation by glycerol trinitrate. These findings suggest that, on the one hand NO is not required for the toxicity of TNF in murine hepatocytes. On the other hand, NO did not prevent cytotoxicity in this in vitro model when present in excess. The lack of protection by exogenously applied NO in this in vitro model compared with the protection seen in vivo may be explained by physiological reactions that cannot take place in vitro such as prevention of ischemia/reperfusion by SNP-induced vasodilatation.

The reason why hepatocytes prepared from IL-1tolerant mice are sensitive to ActD/TNF $\alpha$ induced cytotoxicity is not known. It is conceivable that the protection conferred by proteins synthesized in the liver is indirectly mediated through the interaction with extrahepatic cells, e.g., liver-derived proteins such as $\alpha_{1}$ acid glycoprotein, may cause the release of anti-inflammatory glucocorticoids from the adrenals. Alternatively, protection might be mediated directly by plasma proteins synthesized by the liver. ${ }^{40}$ Such proteins may not be present in sufficient amounts in cell cultures.

The role of endogenously produced NO in septic shock and other inflammatory models is not yet clarified. To study the significance of $\mathrm{NO}$ in TNF $\alpha$-induced liver failure in GalN-sensitized mice and to further investigate the role of endogenously formed NO for the development of tolerance, we examined whether injection of an NO-releasing agent (SNP) in vivo could protect against $\mathrm{TNF} \alpha$ toxicity and what effects inhibition of NOS might have on IL-1-induced tolerance. The finding that SNP protected against TNF $\alpha$-induced hepatotoxicity is consistent with findings in the GalN/ LPS model where various vasodilatators were protective. ${ }^{41}$ An increased production of NO is probably responsible for the detrimental decrease in blood pressure seen in septic shock, ${ }^{42,43}$ and knock-out mice lacking the inducible NOS show decreased sensitivity towards LPS-induced lethality. ${ }^{43,44}$ Nevertheless, beneficial effects of this mediator in sepsis have also been described. For instance, an aggravation of LPS-induced hepatic damage in Corynebacterium parvum-sensitized mice by administration of NMMA, a competitive inhibitor of NOS, was reported ${ }^{14,15}$ and inhibition of endogenous NO production increased lethality in staphylococcal enterotoxin-B-induced shock in mice. ${ }^{45}$ Furthermore, whereas NMMA administered to a patient in septic shock increased blood pressure as expected, it finally led to intravascular coagulation and death. ${ }^{46}$ The aggravation of septic complications by inhibition of NO formation on the one hand and the protection against $\mathrm{TNF} \alpha$ conferred by SNP on the other hand suggest beneficial effects of endogenously produced NO. However, we observed that NMMA administration did not abolish IL-1-induced tolerance although the increase in serum nitrite/nitrate levels induced by IL-1 pretreatment was shown to be completely prevented. This argues against a predominant role of endogenously produced NO in this inflammatory 
model and against a role of $\mathrm{NO}$ in the development of tolerance.

In summary, IL-1 pretreatment protected GalN-sensitized mice against TNF $\alpha$ induced hepatotoxicity. Although IL-1 increased NO release of liver cells in vivo and ex vivo and although treatment with the NO donor SNP was protective against $\mathrm{TNF} \alpha$ toxicity, endogenously produced NO had no effect on IL-1 induced tolerance in vivo nor on TNF $\alpha$ mediated cytotoxicity in vitro in the presence of ActD. We conclude that IL-1 induces expression and/or release of tolerance-inducing proteins different from NOS and that increased production of endogenous $\mathrm{NO}$ is not the mechanism responsible for tolerance development.

Acknowledgment: We thank Dr Adolf for the generous gift of rmuTNF $\alpha$ and Dr K. Vosbeck for kindly providing rhuIL-1 $\beta$. The perfect technical assistance of M. Ullmann, C. Sondern, and J. Schümann is gratefully acknowledged. Special thanks to $\mathrm{Dr} H$. Blüthmann for helpful discussion and to Dr P.-G. Germann for help in histological examinations.

\section{REFERENCES}

1. Waage A. Presence and involvement of TNF in septic shock. In: Beutler B, ed. Tumor necrosis factors. The molecules and their emerging role in medicine. New York: Raven, 1992:275-283.

2. Lehmann V, Freudenberg MA, Galanos C. Lethal toxicity of lipopolysaccharide and tumor necrosis factor in normal and D-galactosamine-treated mice. J Exp Med 1987;165:657-663.

3. Tiegs G, Wolter M, Wendel A. Tumor necrosis factor is a terminal mediator in galactosamine/endotoxin-induced hepatitis in mice. Biochem Pharmacol 1989;38:627-631.

4. Wallach D, Holtmann H, Engelmann H, Nophar Y. Sensitization and desensitization to lethal effects of tumor necrosis factor and IL-1. J Immunol 1988; 140:2994-2999.

5. Libert C, van Bladel S, Brouckaert P, Shaw A, Fiers W. Involvement of the liver, but not of IL-6, in IL-1-induced desensitization to the lethal effects of tumor necrosis factor. J Immunol 1991; 146:2625-2632.

6. Freudenberg MA, Galanos C. Induction of tolerance to lipopolysaccharide (LPS)-D-galactosamine lethality by pretreatment with LPS is mediated by macrophages. Infect Immunol 1988;56:1352-1357.

7. Moncada S, Palmer RMJ, Higgs EA. Nitric oxide: physiology, pathophysiology, and pharmacology. Pharmacol Rev 1991;43: 109-142.

8. Ignarro LJ, Bugy GM, Wood KS, Byrns RE, Chaudhuri G. Endothelium-derived relaxing factor produced and released from artery and vein is nitric oxide. Proc Natl Acad Sci U S A 1987;84:9265-9269.

9. Stuehr DJ, Marletta MA. Induction of nitrite/nitrate synthesis in murine macrophages by BCG infection, lymphokines or interferon- $\gamma$. J Immunol 1987; 139:518-525.

10. Stadler J, Bergonia HA, Di Silvio M, Sweetland MA, Billiar TR, Simmons RL, Lancaster JR Jr. Nonheme iron-nitrosyl complex formation in rat hepatocytes: detection by electron paramagnetic resonance spectroscopy. Arch Biochem Biophys 1993;302:4-11.

11. Adamson GM, Billings RE. Cytokine toxicity and induction of NO synthase activity in cultured mouse hepatocytes. Toxicol Appl Pharmacol 1993;119:100-107.

12. Geller DA, Lowenstein CJ, Shapiro RA, Nussler AK, Di Silvio M, Wang SC, Nakayama DK, et al. Molecular cloning and expression of inducible nitric oxide synthase from human hepatocytes. Proc Natl Acad Sci U S A 1993;90:3491-3495.

13. Helyar L, Bundschuh DS, Laskin JD, Laskin DL. Induction of hepatic Ito cell nitric oxide production after acute endotoxemia. HEPATOLOGY 1994;20:1509-1515.

14. Harbrecht BG, Billiar TR, Stadler J, Demetris AJ, Ochoa JB, Curran RD, Simmons RL. Nitric oxide synthesis serves to reduce hepatic damage during acute murine endotoxemia. Crit Care Med 1992;20:1568-1574.

15. Harbrecht BG, Billiar TR, Stadler J, Demetris AJ, Ochoa J, Curran RD, Simmons RL. Inhibition of nitric oxide synthesis during endotoxemia promotes intrahepatic thrombosis and an oxygen radical-mediated hepatic injury. J Leukoc Biol 1992;52:390-394.

16. Cobb JP, Natanson C, Hoffman WD, Lodato RF, Banks S, Koev CA, Solomon MA, et al. $N^{\omega}$-amino-L-arginine, an inhibitor of nitric oxide synthase, raises vascular resistance but increases mortality rates in awake canines challenged with endotoxin. J Exp Med 1992;176:1175-1182.

17. Shultz PJ, Raij L. Endogenously synthesized nitric oxide prevents endotoxin-induced glomerular thrombosis. J Clin Invest 1992;90:1718-1725.

18. Eizirik DL, Björklund A, Welsh N. Interleukin-1-induced expression of nitric oxide synthase in insulin-producing cells is preceded by c-fos induction and depends on gene transcription and protein synthesis. FEBS Lett 1993;317:62-66.

19. Geller DA, Nussler AK, Di Silvio M, Lowenstein CJ, Shapiro RA, Wang SC, Simmons RL, et al. Cytokines, endotoxin, and glucocorticoids regulate the expression of inducible nitric oxide synthase in hepatocytes. Proc Natl Acad Sci U S A 1993;90:522526.

20. Sheppard BC, Norton JA. Tumor necrosis factor and interleukin1 protection against the lethal effects of tumor necrosis factor. Surgery 1991;109:698-705.

21. Leon P, Redmond HP, Shou J, Daly JM. Interleukin-1 and its relationship to endotoxin tolerance. Arch Surg 1992;127:146151.

22. Leist M, Gantner F, Bohlinger I, Germann PG, Tiegs G, Wendel A. Murine hepatocyte apoptosis induced in vitro and in vivo by TNF- $\alpha$ requires transcriptional arrest. J Immunol 1994;153: 1778-1788.

23. Seglen PO. Preparation of isolated rat liver cells. Methods Cell Biol 1976; 13:29-83.

24. Klaunig JE, Goldblatt PJ, Hinton DE, Lipsky MM, Chacko J, Trump BF. Mouse liver cell culture I. Hepatocyte isolation. In Vitro 1981; 17:913-925.

25. Doolittle RL, Richter GW. Isolation and culture of Kupffer cells and hepatocytes from single rat livers. With observations on iron-loaded Kupffer cells. Lab Invest 1981;45:558-566.

26. Bergmeyer HU. Methods of enzymatic analysis. Weinheim: Verlag Chemie, 1984.

27. Kingsley ED, Gray P, Tolman KG, Tweedale R. The toxicity of metabolites of sodium valproate in cultured hepatocytes. $\mathrm{J}$ Clin Pharmacol 1983;23:178-185.

28. Mosmann T. Rapid colorimetric assay for cellular growth and survival: application to proliferation and cytotoxicity assays. $\mathrm{J}$ Immunol Methods 1983;65:55-63.

29. Espevik T, Nissen-Meyer J. A highly sensitive cell line WEHI 164 clone 13 , for measuring cytotoxic factor/tumor necrosis factor from human monocytes. J Immunol Methods 1986;95:99-105.

30. Misko TP, Schilling RJ, Salvemini D, Moore WM, Currie MG. A fluorimetric assay for the measurement of nitrite in biological samples. Anal Biochem 1993;214:11-16.

31. Zar JH. Biostatistical analysis. New Jersey: Prentice-Hall, 1984.

32. Cavaillon JM, Pitton C, Fitting C. Endotoxin tolerance is not a LPS-specific phenomenon: partial mimicry with IL-1, IL-10 and TGF $\beta$. J Endotox Res 1994;1:21-29.

33. Wendel A. Biochemical pharmacology of inflammatory liver injury in mice. Methods Enzymol 1990; 186:675-680.

34. Leist M, Gantner F, Bohlinger I, Tiegs G, Germann P-G, Wendel A. Tumor necrosis factor-induced hepatocyte apoptosis precedes liver failure in experimental murine shock models. Am J Pathol 1995; 146:1220-1234.

35. Decker K, Keppler D. Galactosamine hepatitis: key role of the nucleotide deficiency period in the pathogenesis of cell injury and cell death. Rev Physiol Biochem Pharmacol 1974;71:77-100. 
36. Wong GHW, Elwell JH, Oberley LW, Goeddel DV. Manganous superoxide dismutase is essential for cellular resistance to cytotoxicity of tumor necrosis factor. Cell 1989;58:923-931.

37. Hirose K, Longo DL, Oppenheim JJ, Matsushima K. Overexpression of mitochondrial manganese superoxide dismutase promotes the survival of tumor cells exposed to interleukin-1, tumor necrosis factor, selected anticancer drugs, and ionizing radiation. FASEB J 1993; 7:361-368.

38. Masuda A, Longo DL, Kobayashi Y, Appella E, Oppenheim JJ, Matsushima K. Induction of mitochondrial manganese superoxide dismutase by interleukin 1. FASEB J 1988;2:3087-3091.

39. Rogers JT, Bridges KR, Durmowicz GP. Translational control during the acute phase response. J Biol Chem 1990;65:1457214578.

40. Libert C, Brouckaert P, Fiers W. Protection by $\boldsymbol{\alpha}_{1}$-acid glycoprotein against tumor necrosis factor-induced lethality. J Exp Med 1994; 180:1571-1575.

41. Wendel A, Tiegs G, Werner C. Evidence for the involvement of a reperfusion injury in galactosamine/endotoxin-in- duced hepatitis in mice. Biochem Pharmacol 1987;36:26372639.

42. Petros A, Lamb G, Leone A, Moncada S, Bennett D, Vallance P. Effects of a nitric oxide synthase inhibitor in humans with septic shock. Cardiovasc Res 1994;28:34-39.

43. MacMicking JD, Nathan C, Hom G, Chartrain N, Fletcher DS, Trumbauer M, Stevens K, et al. Altered responses to bacterial infection and endotoxic shock in mice lacking inducible nitric oxide synthase. Cell 1995;81:641-650.

44. Wel X-Q, Charles IG, Smith A, Ure J, Feng G-J, Huang F-P, Xu $\mathrm{D}$, et al. Altered immune responses in mice lacking inducible nitric oxide synthase. Nature 1995;375:408-411.

45. Florquin S, Amraoui Z, Dubois C, Decuyper J, Goldman M. The protective role of endogenously synthesized nitric oxide in staphylococcal enterotoxin B-induced shock in mice. J Exp Med 1994; 180:1153-1158.

46. Petros A, Bennett D, Vallance P. Effect of nitric oxide synthase inhibitors on hypotension in patients with septic shock. Lancet 1991;338:1557-1558. 